\title{
Gold-induced immune complex nephritis in seronegative rheumatoid arthritis
}

\author{
B. V. SKRIFVARS, T. S. TÖRNROTH, AND G. N. TALLQVIST \\ From the Fourth Department of Medicine, Helsinki University Central Hospital; Departments of Pathology, \\ Maria and Aurora Hospitals; and Municipal Bacteriological Laboratory, Aurora Hospital, Helsinki
}

SUMMARY Proteinuria, with or without the nephrotic syndrome, developed in 8 patients with seronegative rheumatoid arthritis after the institution of gold therapy. Light microscope examination of renal biopsies showed normal findings in 7, and a focal increase in the mesangial matrix of one glomerulus in the eighth. In all patients immunofluorescence showed deposits of IgG and C3 along the glomerular basement membrane, indicative of immune complex nephritis. The renal biopsies of 5 patients were studied with the electron microscope and subepithelial deposits were detected in all. The Rose-Waaler test for the detection of IgM-rheumatoid factor (IgM-RF) was repeatedly negative in all patients. These results suggest that the development of gold nephropathy may be related to an absence of IgM-RF in serum.

The paucity of reports on renal complications caused by gold salts in the treatment of rheumatoid arthritis (RA) reflects the rarity of these complications. Among rheumatoid patients receiving gold therapy the nephrotic syndrome and massive proteinuria have been reported in less than 1\% (Hartfall et al., 1937), and mild transient proteinuria in 1 to $3 \%$ (Empire Rheumatism Council, 1961). A review of the literature showed only one case of acute tubular necrosis (Derot et al., 1954).

Gold salts are rapidly resorbed (Krusius et al., 1970), bound to plasma proteins, and deposited in lymphatic tissues, liver, and spleen (Gottlieb et al., 1972). In the kidneys gold salts accumulate in the proximal tubules where gold inclusions can be shown within a few hours of administration (Brun et al., 1964). Although they are thought to be excreted mainly via the tubules (Brun et al., 1964), gold salts have also been shown to pass through the glomerular basement membrane (Strunk and Ziff, 1970).

We describe the clinical and renal biopsy findings, emphasizing the results of serological and immunofluorescence studies, in 8 patients with RA in whom proteinuria with or without the nephrotic syndrome developed after gold salt treatment was started.

Accepted for publication March 3, 1977

Correspondence to Dr. B. Skrifvars, Helsinki University Central Hospital, Fourth Department of Medicine, Unioninkatu 38, 00170 Helsinki 17, Finland

\section{Materials and methods}

In 8 patients ( 7 females, 1 male) the nephrotic syndrome or proteinuria $(>0.2 \mathrm{~g} / \mathrm{l})$ developed during treatment with sodium aurothiomalate (Myocrisin). All 8 patients had chronic, erosive polyarthritis; none had shown signs of renal disease before starting gold therapy. Table 1 and Fig. 1 give the clinical details. In none of the patients was amyloid detected. Renal biopsy specimens, obtained by a Menghini needle, were divided into two pieces, one for immunohistochemical study, the other for examination by light and electron microscopy.

For immunofluorescence study the tissue was quenched in Freon 22, chilled in liquid nitrogen, and sectioned at 4 to $6 \mu \mathrm{m}$ in a cryostat at $-24^{\circ} \mathrm{C}$. The sections were washed in phosphate-buffered saline (PBS) for 10 minutes, incubated for 45 minutes with fluorescein-conjugated antisera against human IgG, IgM, IgA, complement component C3, and fibrinogen, then washed in two changes of PBS for 20 minutes each time, and mounted in glycerinebuffered glycerol. Antisera were prepared as described elsewhere (Wager et al., 1971). The intensity of the fluorescence was graded from +1 to +4 . Similarly treated sections of normal human renal tissue served as control material.

For examination by light and electron microscope, tissue specimens were fixed in $1.5 \%$ glutaraldehyde. Sections for light microscopy were stained with 


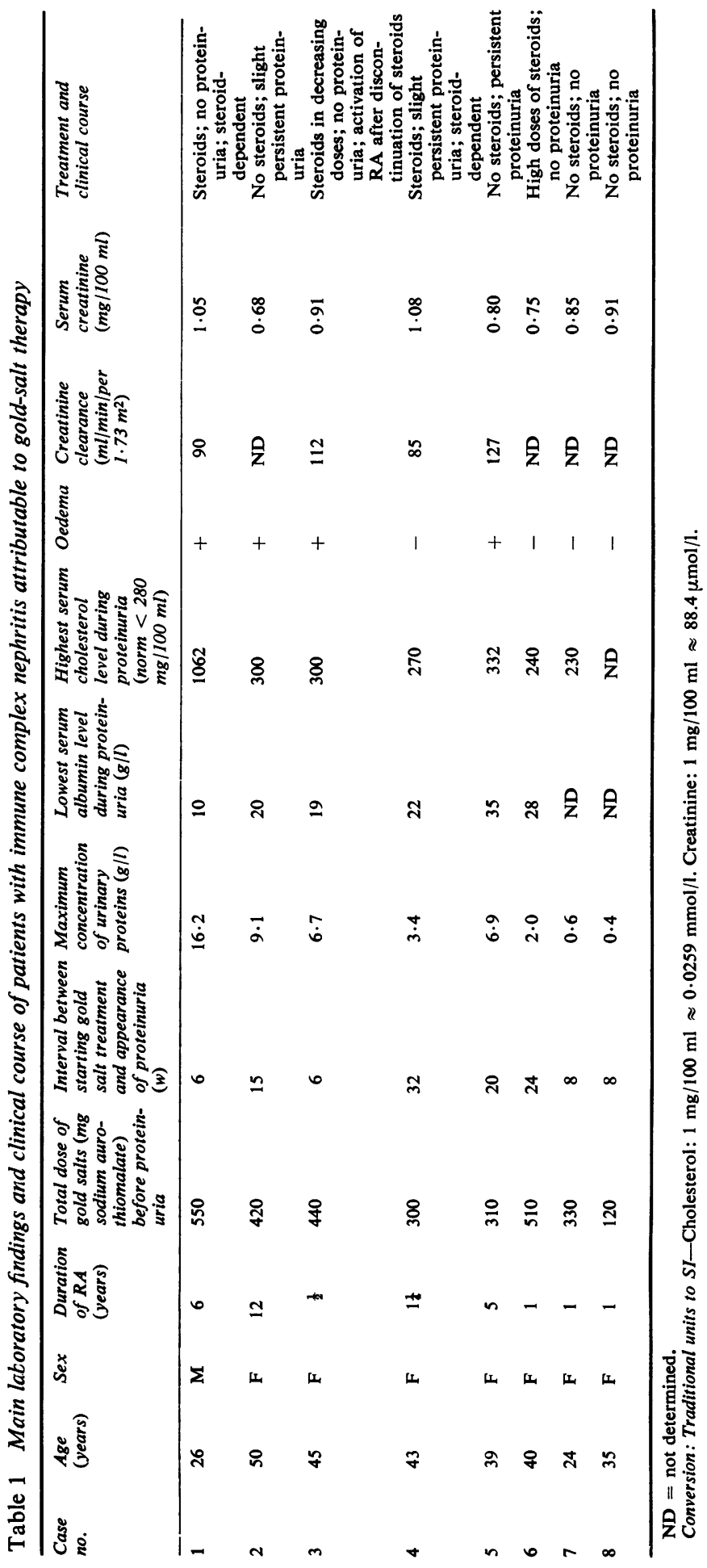




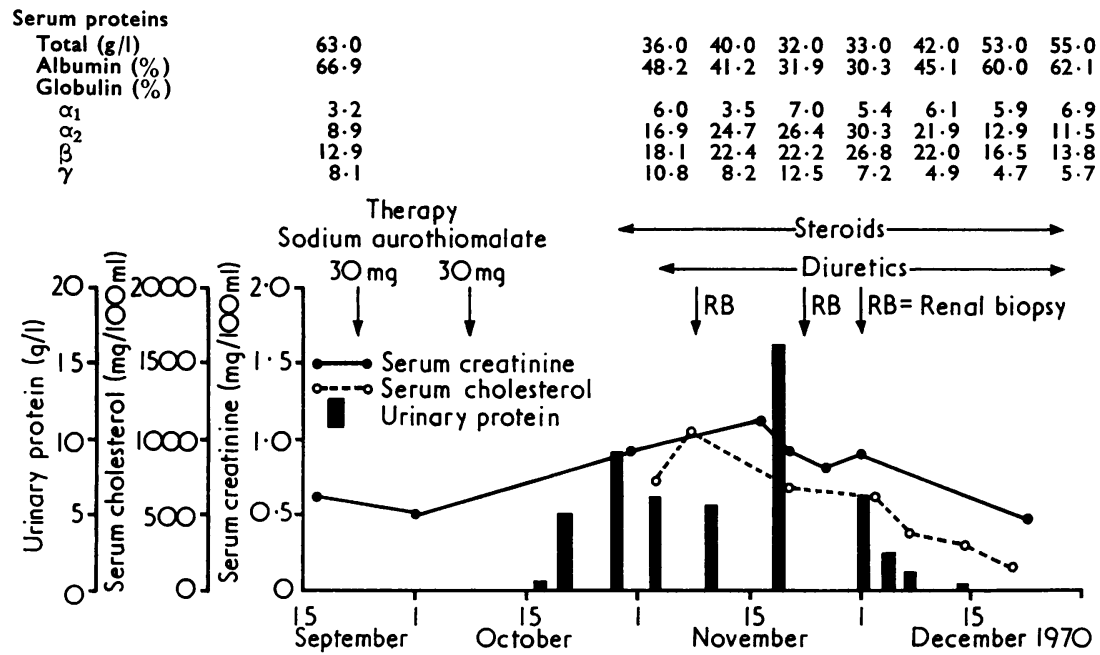

Fig. 1 A 26-year-old lorry driver who had had erosive polyarthritis since 1964 was seen in spring 1970 suffering from an acute deterioration of this condition with weight loss, morning stiffness, and involvement of finger joints, knees, and ankles. In April 1970 simultaneous treatment with sodium aurothiomalate (Myocrisin) and prednisone was started; in September a synovectomy of the proximal interphalangeal joints was performed. Primary urine analysis normal; no proteinuria. Serum creatinine $0.6 \mathrm{mg} / 100 \mathrm{ml}(53 \mu \mathrm{mol} / \mathrm{l})$; Rose-Waaler titre <32; latex fixation test negative. The steroid was withdrawn but treatment with gold salts was continued. Proteinuria was first detected in mid-October, and by November 20 maximum urinary proteins had reached $16 \cdot 2 \mathrm{~g} / \mathrm{l}$. Total serum proteins fell to $32 \mathrm{~g} / \mathrm{l}$, of which albumin constituted $31.9 \%$. Serum cholesterol level gradually rose to $1062 \mathrm{mg} / 100 \mathrm{ml}(27.5 \mathrm{mmol} / \mathrm{l})$. Renal function normal; creatinine clearance $90 \mathrm{ml} / \mathrm{min}$. A percutaneous renal biopsy was performed early in November but light microscope examination showed no histopathological changes. In the tissue specimen obtained in a second biopsy 3 weeks later immunofluorescence showed granular deposits of immunoglobulin and C3 along the glomerular capillary walls. Intensive steroid therapy was begun (methylprednisolone $40 \mathrm{mg}$ daily) and had a favourable effect on the nephrotic syndrome. See footnote to Table 1 for conversion factors for serum cholesterol and creatinine.

haematoxylin and eosin, periodic acid-Schiff (PAS), periodic acid-silver methenamine (PASM), thioflavine T, and Congo red. Nonspecific PAS staining was eliminated by immersing sections in a mixture of concentrated glacial acetic acid and aniline oil (Yanoff et al., 1965; Chambers et al., 1968).

In the Rose-Waaler test, human O Rh-positive erythrocytes were sensitized with rabbit antihuman erythrocyte serum. The test was carried out with U-microplates, and Microtiter equipment. Results were recorded after incubation of the suspension overnight at $+4^{\circ} \mathrm{C}$, with a titre of $1: 64$ regarded as positive. The latex fixation test was performed with the one-tube technique of Singer and Plotz (1958); the results were graded as,$- 1+, 2+, 3+$, or $4+$. Neither synovial tissue nor fluid was tested for the presence of IgM-rheumatoid factor.

\section{Results}

Table 2 summarizes the findings on light microscopy and by direct immunofluorescence. In 7 of the 8 patients, light microscope findings were normal; all glomeruli showed a smooth basement membrane free of spikes or other irregularities (Fig. 2). In the remaining patient (Case 5) 9 glomeruli out of 10

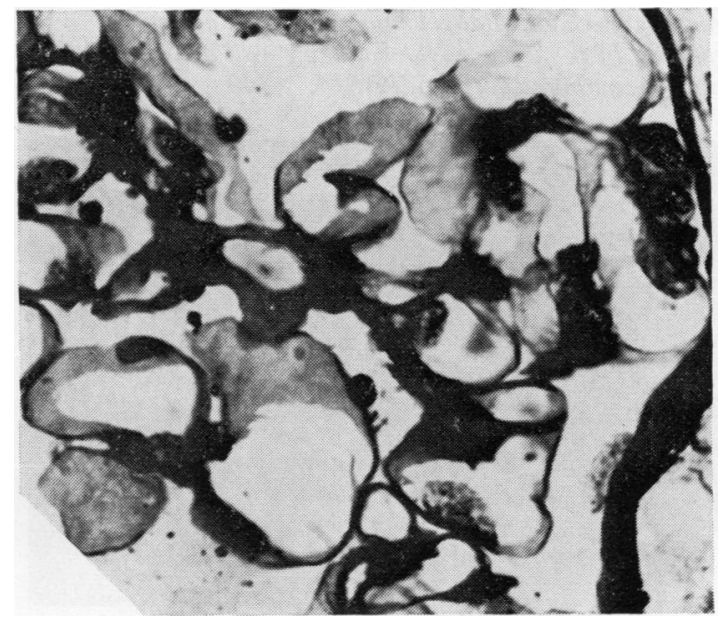

Fig. 2 Paraffin section showing part of a glomerulus. The capillary basement membrane is not thickened and has no 'spikes'. Periodic acid-silver methenamine $(P A S M) . \times 1100$. 
Table 2 Light microscope and immunofluorescence findings in renal biopsy specimens in gold-induced immune complex nephritis

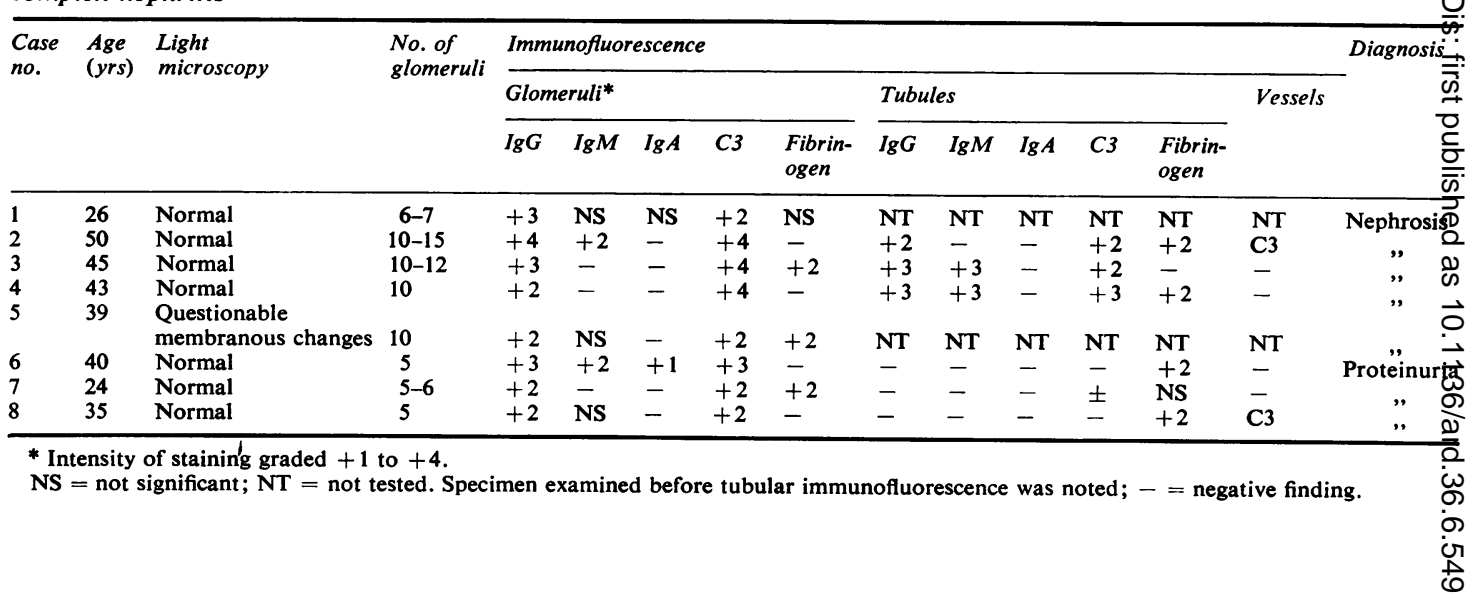

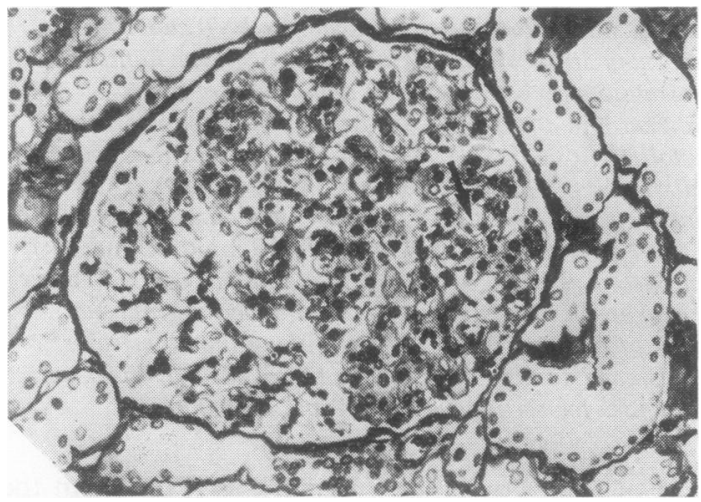

Fig. 3 Case 5. Section of right half of glomerular capillary tuft is moderately condensed with proliferated mesangial-endothelial cells and increased mesangial matrix. In some places the capillary wall appears double-contoured (arrow). PASM. $\times 140$.

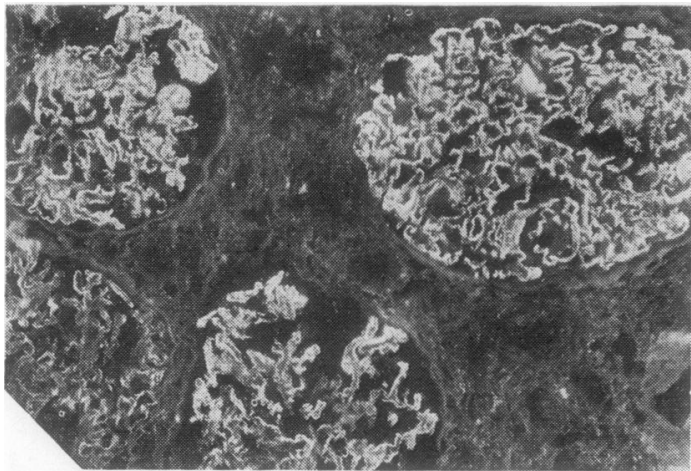

Fig. 4 Case 2. Cryostat section stained with anti-IgG showing 4 glomeruli with finely granular deposits of $\lg G$ along the capillary walls. The glomerulus in the lower left corner is most weakly stained. $\times 140$. appeared normal. In one region of the tenth glomes ulus proliferating mesangial cells and a thickened mesangial matrix had encroached upon capillar lumina and double-contoured capillary walls (Fig. 3

With immunofluorescence all glomeruli of all patients stained positively for IgG and C3. The staining localized to capillary walls, and was always finely granular. In 6 patients, the distribution of and $\mathrm{C} 3$ was diffuse throughout the whole glomerums: in 2 the distribution was both focal and diffise (Figs. 4-7).

In only 2 patients (Cases 2 and 6) did glomeru stain positively for IgM, with the staining localize to the mesangial region (Fig. 8). In Case $6 \operatorname{IgA}$ wa今 detected in the glomeruli, and in Cases 2 and $8 \mathrm{C} \overrightarrow{\mathrm{\sigma}}$

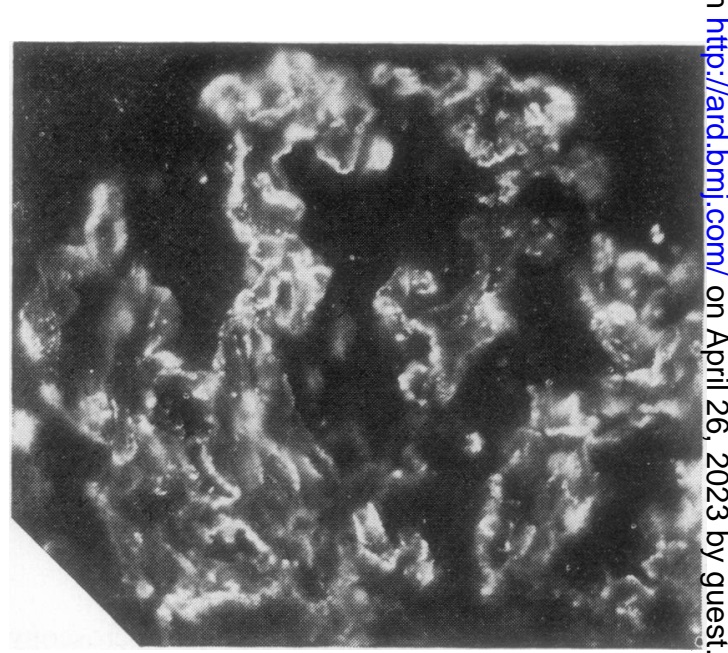

Fig. 5 Case 2. Part of a glomerulus stained with anti-C3. The staining pattern is similar to that in Fig. 4 $\times 450$. 


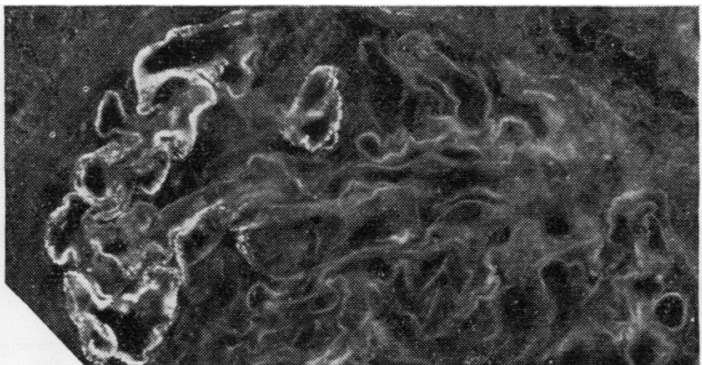

Fig. 6 Case 4. Cryostat section of a part of a glomerulus stained with anti-IgG. Notice the segmental (focal) distribution of IgG within the capillary tuft. $\times 320$.

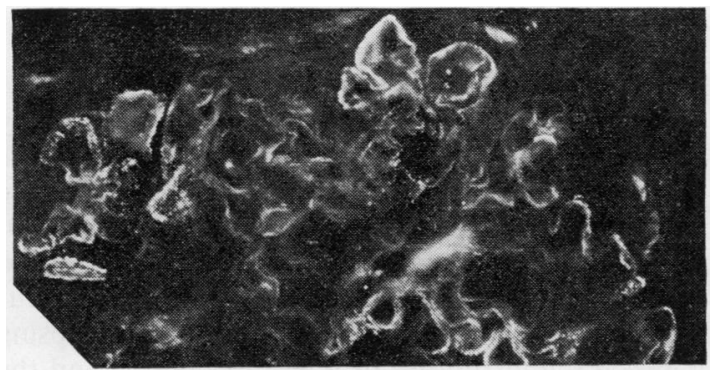

Fig. 7 Case 4. Cryostat section stained with anti-C3 showing a similarly segmental distribution of the capillary deposits. $\times 320$.

was shown in the walls of arterioles. In 3 patients who had the nephrotic syndrome or heavy proteinuria, IgG, IgM, and C3 were present in tubules, IgG and IgM being detected in the tubular epithelial cells, and $\mathrm{C} 3$ along the tubular basem $2 n t$ membrane (Fig. 9).

Tissue from 5 patients was available for electron microscope study. In all 5 specimens electron-dense deposits or electron-lucent areas were seen on the external surface (i.e. subepithelially) or within the basement membrane of the glomerular capillaries (Figs. 10,11). The deposits were usually associated with projections and slight irregular thickenings of the basement membrane. As a rule, such basement membrane changes (deposits and projections) occurred in clusters and affected only parts of the capillary tuft. Only rarely were all capillary loops diffusely affected.

This apparent discrepancy between findings from electron microscopy and immunofluorescence studies can probably be explained by the great difference in the thickness of the sections studied with these techniques. A detailed report of the electron microscope findings has been published elsewhere (Törnroth and Skrifvars, 1974).

Table 3 shows the results of the Rose-Waaler and latex fixation tests in detecting IgM-rheumatoid factor (IgM-RF). In 2 patients (Cases $3 \& 8$ ) the Rose-Waaler test was slightly positive during the acute phase of the illness. However, in all patients, once proteinuria had developed the Rose-Waaler tests were negative.

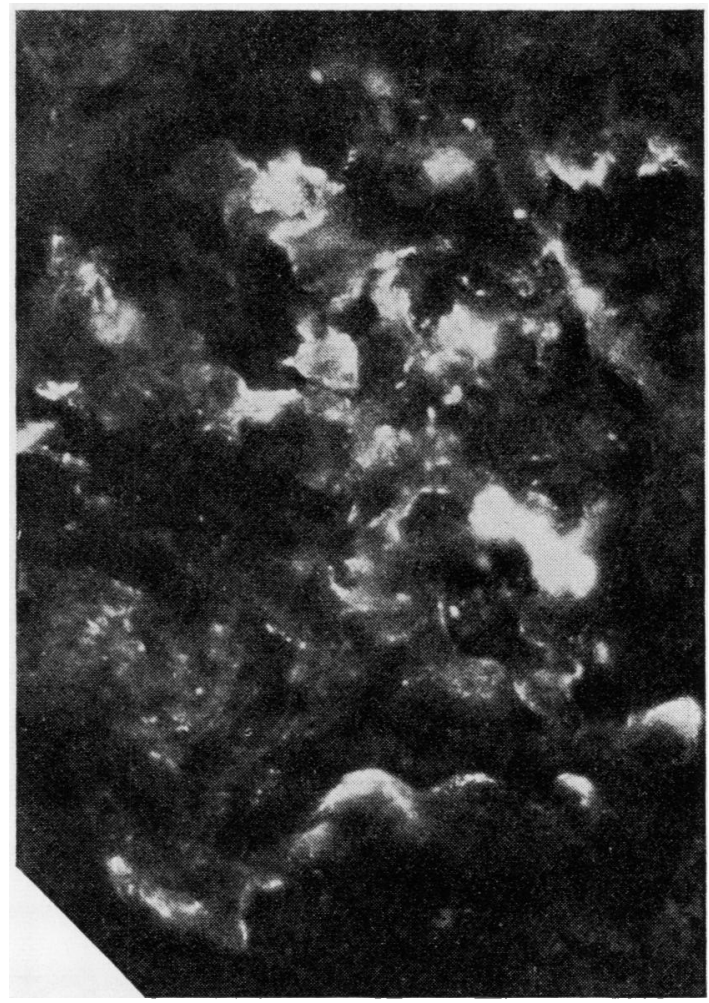

Fig. 8 Case 2. Cryostat section of a glomerulus stained with anti-IgM. Coarse granular deposits of IgM are localized predominantly in the mesangial areas. $\times 650$.

Table 3 Serological tests for rheumatoid factor in patients with immune complex nephritis attributable to gold salt treatment

\begin{tabular}{lclcl}
\hline $\begin{array}{l}\text { Case } \\
\text { no. }\end{array}$ & $\begin{array}{l}\text { Rose-Waaler } \\
\text { test }\end{array}$ & $\begin{array}{l}\text { No. of } \\
\text { tests }\end{array}$ & $\begin{array}{l}\text { Latex } \\
\text { test }\end{array}$ & $\begin{array}{l}\text { No. of } \\
\text { tests }\end{array}$ \\
\hline 1 & $64^{*}$ & 1 & +2 & 1 \\
2 & $<32$ & 4 & 0 & 4 \\
& 64 & 1 & +2 & 1 \\
3 & $<32$ & 8 & +1 & 3 \\
& 128 & 2 & 0 & 5 \\
4 & 64 & 1 & +3 & 2 \\
5 & $<32$ & 4 & +1 & 1 \\
6 & $<32$ & 9 & 0 & 4 \\
& $<32$ & 3 & 0 & 9 \\
7 & 64 & 1 & 0 & 3 \\
8 & $<32$ & 3 & +3 & 1 \\
& $<32$ & 6 & 0 & 2 \\
& 250 & 1 & +1 & 1 \\
& $<32$ & 2 & 0 & 2 \\
\hline
\end{tabular}

* Rose-Waaler titre $\leqslant 64$ negative. 


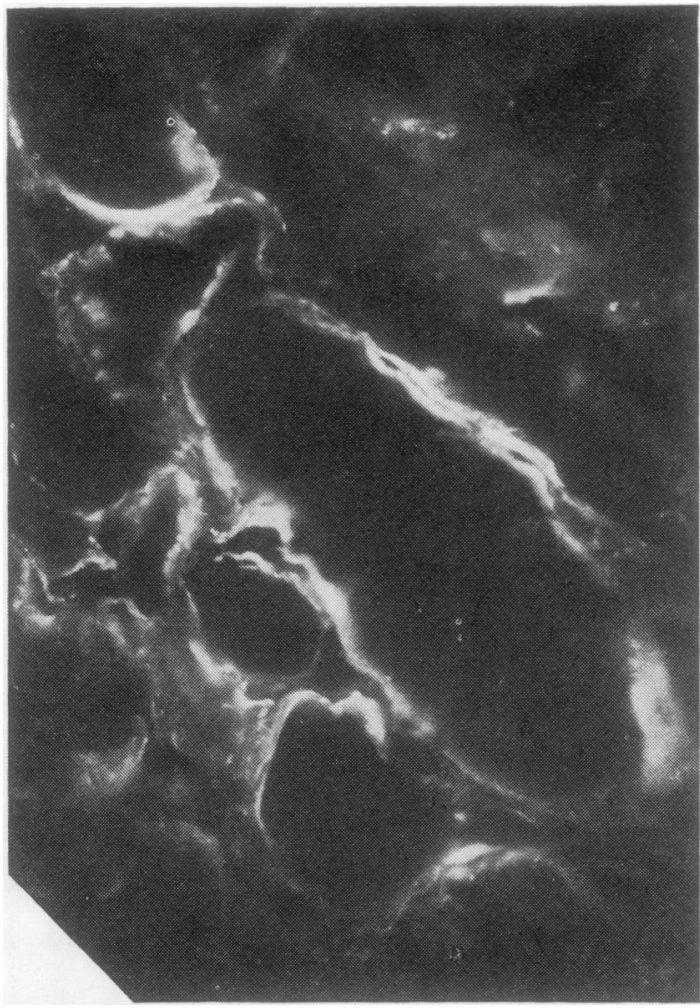

Fig. 9 Case 4. Cryostat section stained with anti-C3 showing specific staining in the regions of the basement of proximal tubuli. $\times 580$.

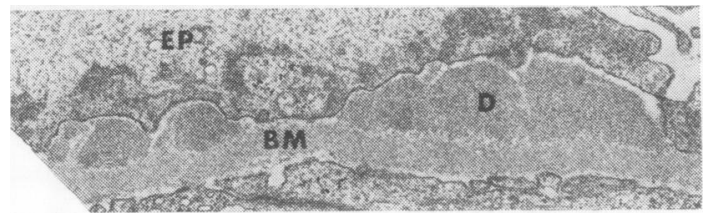

Fig. 10 Case 2. Electron micrograph showing multiple electron-dense deposits $(D)$ on the external surface on the glomerular capillary basement membrane (BM), which otherwise appears normal. $E P=$ epithelial cell. $\times 11900$.

\section{Discussion}

In the 8 patients studied proteinuria developed with or without the nephrotic syndrome after starting gold salt therapy. The lapse of time between the start of treatment and the development of proteinuria ranged from 6 to 32 weeks. In 2 patients, given both gold and steroids, proteinuria developed after discontinuation of steroid treatment.

That gold treatment caused the proteinuria cannot

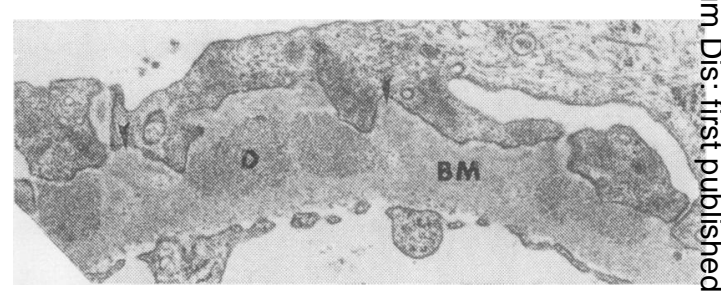

Fig. 11 Case 4. Electron micrograph. The glomerular capillary basement membrane $(B M)$ is irregularly thickened as a result of deposits $(D)$, partly incorporated $\overrightarrow{.}$ in the basement membrane, alternating with projections (arrow-heads) from the basement membrane. These changes were not visible in the paraffin-embedded sections. $\times 11900$.

be claimed with certainty because proteinuria max̧大 be present in rare cases of rheumatoid arthritis without gold having been administered (EmpireRheumatism Council, 1961). Silverberg et al. (19709 reached this same conclusion in their study of goles nephropathy and proteinuria. Nevertheless, in ous 8 seronegative patients the short time elapsin between the institution of gold salt therapy and the. development of proteinuria does suggest a catsisal relationship. Furthermore, proteinuria attributa le to the rheumatoid arthritis itself is generally thought to occur predominantly in seropositive patients whe have severe systemic manifestations.

In all 8 patients immunofluorescence showed finel granular deposits of IgG and C3 along the glomerula® capillary walls. This staining pattern, along with th $\vec{\delta}$ ultrastructural findings, suggests the presence of immune complexes in the glomeruli (Germuth and Rodriquez, 1973; Wilson and Dixon, 1974). Involve? ment of immune complexes in the pathogenesis of gold nephropathy has previously been suggeste from ultrastructural findings (Lee et al., 1965) as well as from the findings in one case studied bot ultrastructurally and immunologically (Katz an Little, 1973).

The presence of immunoglobulins in the epitheliurm and basement membranes of the renal tubules cap in part be explained by the passive reabsorption of globulins leaking through the glomeruli. Latelfs much interest has been focused on the possible involvement of tubular antigens in various ren diseases (Heymann et al., 1959; Klassen et al., 1972G McCluskey and Klassen, 1973). Because gold salt? are known to be capable of injuring tubular epithete ium (Ganote et al., 1966), it is possible that gold ma $\Phi_{\text {}}$ evoke an autoimmune reaction in which tubular celf or basement membrane antigens are released and thereafter, nephrotoxic immune complexes are्p formed.

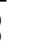


Gold is a drug that accumulates at the sites of inflammation and which may perhaps influence the immune response (Persellin et al., 1967). When administered in large doses, gold salts bind with immunoglobulins, with complement, and with immune complexes (Lorber et al., 1972), events which in turn may correlate with the favourable effect of gold salts on arthritis.

Immune complexes are thought to play an important pathogenetic role in systemic lupus erythematosus and in joint inflammation in rheumatoid arthritis (Carter, 1973). The presence of rheumatoid factorimmunoglobulin aggregates is a manifestation of immune complex formation (Spiegelberg, 1974). Although marked rheumatoid factor seropositivity is generally believed to be associated with a poorer prognosis and with frequent systemic manifestations, such as nodules, skin ulcers, vasculitis, as well as with nephrological and cardiovascular complications, the true pathogenetic role of IgM-RF is still obscure.

All patients in this series were seronegative in the conventional sense as shown by repeatedly negative Rose-Waaler tests; hence their sera contained no appreciable amounts of IgM-RF. Such consistent seronegativity might be evidence of a relationship between the development of gold nephropathy and an absence of IgM-RF in serum. In other words, IgM-RF may be instrumental in preventing gold salt-induced immune complex nephritis.

One prerequisite for the development of this type of immune complex nephritis is the presence of soluble, circulating, nephrotoxic complexes of a size and configuration that would permit their passage through the glomerular basement membrane. It is believed that large immune complexes containing IgM are unable to pass through the basement membrane (Germuth and Rodriquez, 1973), and are trapped in the mesangial region. IgM-RF is a macroglobulin that binds to circulating IgG to form large IgM-IgG-aggregates. Such formation might alter the properties of the pre-existing immune complexes, rendering them larger and less soluble, and thereby available for phagocytosis. Such a hypothesis finds support in the observations (1) by Parker and Schmid (1962) that heat-aggregated gamma globulin is more readily phagocytosed from serum containing RF than from fresh normal serum, and (2) by Britton and Schur (1971) who, in immunofluorescence studies, showed that immune complexes in seropositive RA fix complement and, through the activation of $\mathrm{C} 3$, are phagocytosed by synovial fluid leucocytes. IgM-RF may therefore be endowed with protective properties.

Our results suggest that if sufficient amounts of IgM-RF are present in serum while gold is being administered, a large complex is formed that is disposed of by phagocytosis; if IgM-RF is lacking, however, gold modifies the pre-existing soluble complexes so that they become nephrotoxic and are precipitated in the kidneys.

In none of our patients was the course of the nephrosis lethal. 2 patients became protein-free spontaneously and 3 after receiving decreasing doses of steroids. 2 patients are still receiving steroids.

\section{References}

Britton, M. C., and Schur, P. H. (1971). The complement system in rheumatoid synovitis. Arthritis and Rheumatism, 14, 87-95.

Brun, C., Olsen, S. T., Raaschou, F., and Sørensen, A. W. S. (1964). The localization of gold in the human kidney following chrysotherapy. Nephron, 1, 265-276.

Carter, P. M. (1973). Immune complex disease. Annals of the Rheumatic Diseases, 32, 265-271.

Chambers, R. W., Bowling, M. C., and Grimley, P. M. (1968). Glutaraldehyde fixation in routine histopathology. Archives of Pathology, 85, 18-30.

Derot, M., Kahn, J., Mazalton, A., and Peyrafort, J. (1954). Néphrite anurique aiguë mortelle aprés traitement aurique, chrysocyanose associée. Bulletins et Mémoires de la Société de Médicine de Paris, 70, 234-239.

Empire Rheumatism Council. (1961). Gold therapy in rheumatoid arthritis. Annals of the Rheumatic Diseases, 20, 315-334.

Ganote, C. E., Beaver, D. L., and Moses, H. L. (1966). Renal gold inclusions. Archives of Pathology, 81, 429-438.

Germuth, F. G., Jr., and Rodriquez, E. (1973). Immunopathology of the Renal Glomerulus, 1st ed., p. 26. LittleBrown, Boston.

Gottlieb, N. L., Smith, P. M., and Smith, E. M. (1972). Tissue gold concentration in a rheumatoid arthritic receiving chrysotherapy. Arthritis and Rheumatism, 15, 16-22.

Hartfall, S. J., Garland, H. G., and Goldie, W. (1937). Gold treatment of arthritis. Lancet, 2, 838-842.

Heymann, W., Hackel, D. B., Harwood, S., Wilson, S. G. F., and Hunter, J. L. P. (1959). Production of nephrotic syndrome in rats by Freund's adjuvants and rat kidney suspension. Proceedings of the Society for Experimental Biology and Medicine, 100, 660-664.

Katz, A., and Little, A. H. (1973). Gold nephropathy. Archives of Pathology, 96, 133-136.

Klassen, J., Andres, G. A., Brennan, J. C., and McCluskey, R. T. (1972). An immunologic renal tubular lesion in man. Clinical Immunology and Immunopathology, 1, 69-83.

Krusius, P.-E., Markkanen, A., and Peltola, P. (1970). Plasma levels and urinary excretion of gold during routine treatment of rheumatoid arthritis. Annals of the Rheumatic Diseases, 29, 232-235.

Lee, J. C., Duskin, M., Eyring, E., Engleman, E. P., and Hopper, J. (1965). Renal lesions associated with gold therapy. Arthritis and Rheumatism, 8, 1-13.

Lorber, A., Bovy, R. A., and Chang, C. C. (1972). Relationship between serum gold content and distribution to serum immunoglobulins and complement. Nature New Biology, 236, 250-252.

McCluskey, R. T., and Klassen, J. (1973). Immunologically mediated glomerular, tubular and interstitial renal disease. New England Journal of Medicine, 288, 564-570.

Parker, R. L., and Schmid, F. R. (1962). Phagocytosis of particulate complexes of gammaglobulin and rheumatoid factor. Journal of Immunology, 88, 519-525. 


\section{Skrifvars, Törnroth, Tallqvist}

Persellin, R. H., Hess, E. V., and Ziff, M. (1967). Effect of a gold salt on the immune response. Arthritis and Rheumatism, 10, 99-106.

Silverberg, D. S., Kidd, E. G., Shnitka, T. K., and Ulan, R. A. (1970). Gold nephropathy. Arthritis and Rheumatism, 13, 812-825.

Singer, J. M., and Plotz, C. M. (1958). The latex fixation test for rheumatoid arthritis, using patient's own gammaglobulin. Arthritis and Rheumatism, 1, 142-146.

Spiegelberg, H. L. (1974). Biological activities of immunoglobulins of different classes and subclasses. Advances in Immunology, Vol. 19, p. 285. Ed. by F. J. Dixon and H. G. Kunkel. Academic Press, New York.
Strunk, S. W., and Ziff, M. (1970). Ultrastructural studies of the passage of gold thiomalate across the renal glomerula capillary wall. Arthritis and Rheumatism, 13, 39-52.

Törnroth, T. S., and Skrifvars, B. (1974). Gold nephropath $\overline{\overline{\bar{x}}}$ prototype of membranous glomerulonephritis. American Journal of Pathology, 75, 573-590.

Wager, O., Räsänen, J. A., Haltia, K., and Wasastjerna, CO (1971). M components with antibody activity. Annals of Clinical Research, 3, 86-97.

Wilson, C. B., and Dixon, F. J. (1974). Diagnosis of immunos pathologic renal disease. Kidney International, 5, 389-4016s

Yanoff, M., Zimmerman, L. E., and Fine, B. S. (1965)Glutaraldehyde fixation of whole eyes. American Journat of Clinical Pathology, 44, 167-171. 